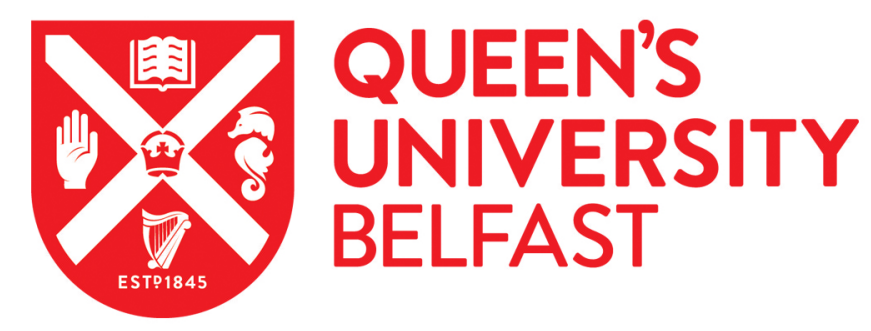

\title{
How financial strain affects health: evidence from the Dutch National Bank Household Survey
}

Prentice, C., McKillop, D., \& French, D. (2017). How financial strain affects health: evidence from the Dutch National Bank Household Survey. Social Science \& Medicine, 178, 127-135.

https://doi.org/10.1016/j.socscimed.2017.02.006

\section{Published in:}

Social Science \& Medicine

\section{Document Version:}

Peer reviewed version

Queen's University Belfast - Research Portal:

Link to publication record in Queen's University Belfast Research Portal

Publisher rights

(c) 2017 Elsevier Ltd. This manuscript version is made available under the CC-BY-NC-ND 4.0 license http://creativecommons.org/licenses/by$\mathrm{nc}-\mathrm{nd} / 4.0 /$, which permits distribution and reproduction for non-commercial purposes, provided the author and source are cited.

\section{General rights}

Copyright for the publications made accessible via the Queen's University Belfast Research Portal is retained by the author(s) and / or other copyright owners and it is a condition of accessing these publications that users recognise and abide by the legal requirements associated with these rights.

Take down policy

The Research Portal is Queen's institutional repository that provides access to Queen's research output. Every effort has been made to ensure that content in the Research Portal does not infringe any person's rights, or applicable UK laws. If you discover content in the Research Portal that you believe breaches copyright or violates any law, please contact openaccess@qub.ac.uk. 


\title{
How financial strain affects health: evidence from the Dutch National Bank Household Survey
}

\begin{abstract}
The mechanisms by which financial strain affects health are not well understood. In this paper, we conduct a longitudinal mediation analysis of the Dutch National Bank Household Survey. To quantify the relative importance of biological and nonbiological pathways from financial strain to health, we consider smoking, heavy drinking and being overweight as plausible behavioural responses to financial strain but find that only $4.9 \%$ of the response of self-reported health to financial strain is mediated by these behaviours. Further analysis indicates that although financial strain increases impulsivity this has little effect on unhealthy behaviours. Economic stresses therefore appear to be distinct from other forms of stress in the relatively minor influence of nonbiological pathways to ill-health.
\end{abstract}

10

Keywords: financial strain, health. 


\section{Introduction}

After the 2008 recession and subsequent sovereign debt crisis, almost half of Europeans stated that unemployment was the most important issue facing their country and, in $2013,41 \%$ said they had difficulties paying bills at least some of the time (Eurobarometer, 2015). Financial

mediate this pathway as individuals become more present-biased when stressed (Haushofer et al., 2015) and higher rates of intertemporal discounting are associated with cigarette 
smoking (Adams, 2009), frequent alcohol consumption (MacKillop and Kahler, 2009), illicit drug use (Coffey et al., 2003), lack of physical exercise (Leonard et al., 2013) and health outcomes such as obesity (Ikeda et al., 2016) and mortality (Boyle et al., 2013).

Although these studies have made the association between financial difficulties and both biological and non-biological pathways to illness no study to date has quantified the relative importance of each of these pathways. This is critical for identifying interventions to mitigate the health consequences of economic downturns as well as austerity programmes. Also, this literature has indicated that both impulsivity and stress are risk factors for negative health behaviours but there has been little work on understanding the causal mechanism from stress to time discounting to worse health-related behaviour especially for economic stresses. This study aims to fill these gaps by testing for the degree to which the effects of financial strain on health are mediated through changes in health behaviours and then analysing the links between financial strain, present-biases and changes in health behaviours in order to better understand the behavioural response to financial strain. We use the Dutch National Bank Household Survey (DNB) which provides us with a large nationally-representative sample of over 40000 observations over a twenty-year period covering the years before and after the financial crisis.

This paper makes the following original contributions. First, we estimate the degree to which the response of health to financial strain is mediated by changes in health behaviours. Although many studies examine the behavioural sequelae of financial strain none quantify the relative importance of this pathway for health. We consider smoking, heavy drinking and being overweight as plausible behavioural responses to financial strain but find that only $4.9 \%$ of the response of self-reported health to financial strain is mediated by these behaviours. Second, we then examine the pathway from financial strain to changes in health behaviours to understand the lack of behavioural response. The DNB dataset is unique in that it collects individual time preference data annually permitting the analysis of variation in time preferences in response to fluctuating levels of financial strain. Using a number 
of different time preference measures, we find evidence that financial strain causes greater impulsivity but this does not lead to worse health behaviours. In this regard, economic stresses appear to be distinct from other forms of stress. Our third contribution is that we address methodological concerns in the literature linking stress and illness. Many studies

5 do not clearly establish evidence for a causal relationship from stress to health Berkman et al., 2014). Using longitudinal data in our study, we test for a temporal ordering that indicates causation from stress to health in our structural model. To avoid concerns about unmeasured confounders driving the relationship between financial strain and ill-health, we use prior levels of the dependent variable in models of all the key variables Cole and Maxwell, 2003) .

The paper is structured as follows. Section 2 details the data and statistical methods. Section 3 presents the results. In Section 4, we discuss our findings with reference to the literature and implications for policymakers.

\section{Methods}

In this paper, we use the Dutch National Bank Household survey which contains a large number of questions about the respondent's financial situation, financial attitudes and health and these questions are generally consistent over a long period of time. A measure of financial strain is constructed using two questions on the household's financial situation. A number of variables used elsewhere in the literature provide us with measures of time preferences. The health measures cover self-reported health, height and weight measurements as well as indicators of health behaviours including smoking and alcohol consumption. An extensive set of household characteristics allow us to control for many social and demographic factors. The longtitudinal survey design allows us to test for mediation effects using the temporal ordering of the variables to account for potential reverse causation. Allowing for multiple mediators, we consider the causal relationship from financial strain to health and also the 
causal relationship from financial strain to changes in health behaviours. These relationships are then estimated over a twenty-year period. The literature on the health consequences of stress would indicate that economic stressors should also impact negatively on health and this effect will be mediated through both nonbiological pathways captured by health behaviours and biological pathways indicated by the non-mediated direct effects. For the mediation analysis of the causal relationship between financial strain and health behaviours, the literature reviewed above would indicate a strong effect largely mediated by changes in time preferences.

The following sections describe the data source, variables used, variables constructed and the statistical methods used in the analysis.

\subsection{Data}

DNB is a panel survey that has been active since 1993. The survey, collected by CentER (Tilburg University, the Netherlands) gathers information annually from approximately 2000 households in separate questionnaires on general information, household and work, accommodation and mortgages, health and income, assets and liabilities and economic and psychological concepts. The survey is unique in that it contains repeated measures of time preferences in a nationally-representative sample. The household characteristics of participants are stored in a database while the household remains part of the panel and therefore this information is largely complete for all respondents. This study uses all waves of data from years 1996 to 2015 as data relevant to our models were particularly sparse in the earliest years of the survey.

The analysis of causal pathways requires repeated measures for individuals and, hence, individuals who did not participate in three consecutive waves of the survey were excluded from the dataset (34945 observations) leaving a dataset of 43858 observations for individuals in participating households aged 16 or over. 


\subsection{Measurement}

\section{Health measures}

Our smoking variable is constructed from responses to the question 'Do you smoke cigarettes at all ?' A response of 'no' was coded as zero in our variable, 'yes, every now

5 you have more than four alcoholic drinks a day?' provide a dichotomous indicator of heavy drinking (Popova et al., 2007). Body mass index was calculated from self-reported responses to questions on height and weight. Respondents with a BMI of over $25 \mathrm{~kg} / \mathrm{m}^{2}$ were considered overweight. Our main measure of health is self-assessed health, which is derived from the question 'In general, would you say your health is?' Answers are given according to a five-point ordinal response scale with categories '5-poor', '4-not so good', '3-fair', '2-good' and '1-excellent'. Self-assessed health has been proven to have value in predicting objective health outcomes, morbidity and mortality (Idler and Benyamini, 1997; Franks et al., 2003). Although, self-reported health assessments are principally assessments of the respondent's degree (Mavaddat et al., 2011). A binary variable was created which was one for those reporting their general health as 'excellent' or 'good' and zero otherwise.

\section{Time preferences}

In the economics literature, time preferences are conventionally represented by time discounting rates derived from experimental elicitation procedures ideally involving real monetary incentives (Frederick et al. 2002). In the absence of such time discounting data over the duration of the period of interest, we used measures of time horizons, preference for spending over saving, difficulty controlling expenditure and future orientation as proxy measures of time preferences. We expect that financial strain increases time discounting leading to an increased incidence of poor health-related behaviours.

Time horizons have been used elsewhere as an index of time preferences in understanding 
saving (Lusardi, 1998; Samwick, 1998) as well as the demand for cancer screening (Picone et al. 2004), adherence to physical activity advice (van der Pol et al., 2016 ) and smoking (Peretti-Watel et al., 2013). In the DNB survey, respondents were asked 'Which of the time-horizons mentioned below is in your household most important with regard to planning expenditures and savings?'. There were five possible responses of increasing duration to this 5 question : 'the next couple of months', 'the next year', 'the next couple of years', 'the next 5 to 10 years' and 'more than 10 years from now'. This variable was coded to make a higher score correspond to shorter time horizons.

Our second measure is preference for spending in terms of discretionary income which was used to measure delay of gratification in Ritzema (1992) and Webley and Nyhus (2006). Respondents were asked how they spent money left over after having paid for food, rent and other necessities on a 7-point scale from 'I like to spend all my money immediately' to 'I want to save as much as possible'. This variable was coded to make a higher score correspond to a greater preference for spending in terms of discretionary income.

The perceived difficulty of controlling expenditure was measured by the question "Many people find it difficult to plan or control their expenditures. Do you find it difficult to control your expenditures?" Individuals respond by using a 7-point scale ranging from '1very easy' to '7-very difficult'. This measure has been used elsewhere as a proxy for the rate of time discounting (Borghans and Golsteyn, 2006) and is an established predictor of savings behaviour (Nyhus, 2002). Rabinovich and Webley (2007) interpret the perceived difficulty of controlling expenditure as a reflection of the general amount of self-control resources available to the respondent but also how effective these resources are in dealing with the task of controlling expenditures.

The final measure is the Consideration of Future Consequences (CFC) scale, a psychological construct used to measure an individual's future orientation (Strathman et al., 1994). Respondents indicate to what extent they agree with the 11 statements on attitudes referring to the trade-off between the present and the future using a 7-point scale (1-completely 
disagree; 7-completely agree). Other studies have used this measure as a proxy for time discounting e.g. (Borghans and Golsteyn, 2006, van Huizen and Plantenga, 2013). When constructing the CFC score, five of the eleven questions were recoded so that a higher score consistently indicated a more present focus. Further detail is provided in the appendix. These questions were not asked in 2008 and, from 2010, they were only asked of those not asked in previous waves. The treatment of missing data is discussed below in section 2.3.

\section{Financial strain}

Our measure of financial strain comes from two survey questions on the household's current financial situation. When asked 'How well can you manage on the total income of your household?' respondents chose from five possible answers : '1-it is very hard','2-it is

10 hard', '3-it is neither hard nor easy', '4-it is easy' and '5-it is very easy'. A second question asked 'How is the financial situation of your household at the moment?' with possible responses: '1-there are debts','2-need to draw upon savings','3-it is just about manageable', '4-some money is saved' and '5-a lot of money can be saved'. A dichotomous financial strain variable was constructed which was one if the response in either of these questions was 1 or 2 and zero otherwise.

\section{Covariates}

A number of covariates were used as control variables. The respondent's gender, highest education level completed, whether they had a partner present in the household and whether they lived in owner-occupied accommodation were represented by binary variables. The twelve categories of response to primary occupation were reduced to a dichotomous indicator of whether employed or not to reduce the number of controls in the model. Age and the number of children in the household entered the model as continuous variables. The survey records net household income as a categorical variable. This was recoded taking the midpoint of each category and upper (lower) interval boundaries for the lowest (highest) category. The average net household income response within household was taken where responses differed 
or the response was missing.

\subsection{Statistical analysis}

Mediation analyses were carried out to first examine the degree to which the effect of financial strain on ill-health is mediated by changes in health behaviours and secondly to examine the degree to which the effect of financial strain on health behaviours is mediated by changes in time preferences.

The basic three wave model is represented in figure 1. The health outcome for person i at time $\mathrm{t}\left(Y_{i t}\right)$ is affected by financial strain from two periods before $\left(S_{i, t-2}\right)$ both directly and indirectly through changes in the mediator $\left(M_{i, t-1}\right)$. Path ab represents the indirect effect via the mediator while path $\mathrm{c}$ represents the direct effect from financial stress to the health outcome not via time discounting.

This part of the model is given in equation form below :

$$
\begin{aligned}
M_{i t-1} & =\delta^{M} M_{i, t-2}+\beta^{a} S_{i, t-2}+\gamma^{M^{\prime}} X_{i, t-1}+\epsilon_{i, t-1}^{M} \\
Y_{i t} & =\delta^{Y} Y_{i, t-1}+\beta^{b} M_{i, t-1}+\beta^{c} S_{t-2}+\gamma^{Y^{\prime}} X_{i t}+\epsilon_{i t}^{Y}
\end{aligned}
$$

The mediating variable $M_{i, t-1}$ depends on its own lag $M_{i, t-2}$ but is additionally affected by financial strain in the previous period $S_{i t-2}$ and a vector of demographic and household characteristics $X_{i, t-1}$. In the first analysis of the effects of financial strain on ill-health, the mediators are smoking, heavy drinking and being overweight while in the second analysis of the effects of financial strain on health behaviours the mediators are time horizons, spending discretionary income, difficulty controlling expenditure and consideration of future consequences . Health outcomes, $Y_{i t}$, are also autoregressive, affected by controls and also affected by financial strain from two periods before $S_{i t-2}$ both directly and indirectly through changes in the mediator(s) in the previous period $M_{i, t-1}$. In the first analysis, the health outcome is self-reported health and in the second analyses the health outcomes are the health be- 
haviours smoking, heavy drinking and being overweight. Lagged dependent variables are included to account for unmeasured and uncontrolled confounder variables that correlate with the predictor variable in the previous period and cause the dependent variable in the current period (Cole and Maxwell, 2003) and also allow modelling of longer-term effects of financial strain.

Additionally, financial strain, $S_{i t}$, is governed by a simple autoregressive model where the only explanatory variable is its own lag $S_{i, t-1}$. The residual from this equation $\epsilon_{i t}^{S}$ and the residuals from the equations above $\epsilon_{i t}^{M}$ and $\epsilon_{i t}^{Y}$ are then allowed correlate to account for contemporaneous changes in unmeasured variables that may be correlated across equations. In the estimation that follows, the primary parameters of interest are the effect(s) of financial strain on the mediator(s) $\beta^{a}$, the effect(s) of the mediator(s) on health outcomes $\beta^{b}$ and the direct effect of financial strain on health outcomes $\beta^{c}$.

We estimate this model on each triplet of three consecutive waves from 1996 (i.e. 1996, 1995 and 1994) to 2015 (i.e. 2015, 2014 and 2013) and constrain parameters to be equal across all twenty triplets. In this way, intercepts and residual variances can vary across time. Bivariate probit models are used in all cases except for time preferences where an ordered probit model was specified. The system was estimated using weighted least squares in Mplus Version 7. Standard errors for the indirect effects were computed using the delta method (Sobel, 1982).

The rate of missing observations is about $40 \%$ for the key variables as participants do not necessarily respond to all questionnaires and to all questions within questionnaire. Multiple imputation (MI) was used to account for both continuous and categorical missing data under the assumption that the data are missing at random (MAR) conditional on observed data. There are no clear limits to the rate of missing data for the purposes of MI Gorelick, 2006; Marsiglia et al., 2010) and some studies suggest rates as high as 60\% are acceptable under the MAR assumption (Kristman et al., 2004). In MI, multiple datasets are generated with imputed values using a Markov Chain Monte Carlo simulation. Parameter estimates 
are then combined across these datasets with standard errors adjusted for variability due to missing data (Rubin Donald, 1987, Schafer, 1997). MI suffers from less parameter estimate bias, provides superior statistical power and takes better account of missing data sampling variability than casewise deletion or alternative missing data approaches (Sterne) et al. 2009, Janssen et al. 2010). Previously observed data on variables in the analysis

5 make the MAR assumption more realistic (Newsom et al., 2013) and were included along with current demographics in the imputation model. In order to yield sufficient statistical power, fifty imputations were carried out (Graham et al., 2007; Enders, 2010). Feng et al. (2013) provide an accessible overview of methodological approaches for dealing with missing data in longitudinal studies.

Although the strength of our study design is that the temporal ordering of financial strain and health consequences in our model controls for potential reverse causation, the cross-wave structure may not capture short-term periods of financial strain which can also impact on health. This is a limitation of the data available to us.

\section{Results}

Descriptive statistics for the sample are given in table 1. Over the period 1996-2015, the percentage of adults reporting financial strain is $12.4 \%$ of the constructed dataset (or $20.9 \%$ of responses). This figure is low by European standards especially post-crisis (Eurobarometer, 2015). Although the majority (77.9\%) report excellent or good health, $23.3 \%$ smoke, $6.7 \%$ are heavy drinkers and 50.5\% are overweight. Over half the sample (54.5\%) have time horizons of a year or less, $10.6 \%$ like to spend all their disposable income immediately, $16.7 \%$ have difficulty controlling their expenditures and, on average, respondents show no preference between distant and future consequences of potential behaviours (average $=4.1$ ).

The results of the mediation analysis of the effects of financial strain on health two years later mediated through changes in health behaviours are given in table 2 . In panel A, higher 
levels of financial strain are seen to be a statistically significant predictor of a greater tendency for heavy drinking $(\beta=0.111)$. On the other hand, there is no clear relationship between financial strain and a propensity for smoking $(\beta=0.026)$ or of being overweight $(\beta=0.044)$. In panel $\mathrm{B}$, the effects of these health behaviours on the probability of reporting good or excellent health indicate that only smoking $(\beta=-0.080)$ and being overweight $(\beta=-0.034)$ probability of self-reporting excellent or good health is relatively large $(\beta=-0.091)$. As a proportion of the overall effect of strain on health, the indirect effect of strain on health mediated through these health behaviours is small at $4.9 \%, p=0.429$ (i.e. $\mathrm{I} /(-0.091+\mathrm{I})=$ 0.049 where total indirect $\left.(\mathrm{I})=0.026^{*}(-0.080)+0.111^{*}(-0.012)+0.044^{*}(-0.034)=-0.005\right)$.

In table 3, we repeat the mediation analysis to examine to what degree the effects of financial strain on health behaviours are mediated through changes in time preferences. The first set of results in panel A are estimates for the effect of strain on time preferences. Financial strain is seen to have a statistically significant effect on three of the four time preference measures used causing an increase in the rate of intertemporal discounting. The strongest impact is on the perceived difficulty of controlling expenditure $(\beta=0.177)$ with a weaker effect on preference for spending disposable income $(\beta=0.066)$ and time horizons $(\beta=0.045)$. These effect sizes are small when the scales of these measures are considered (1-5 for time horizons and 1-7 for the other three time preferences measures). On the other hand, there is no statistically significant effect on the consideration of future consequences $(\beta=-0.010)$. The next set of results in panel $\mathrm{B}$ estimates the effects of time preferences on health behaviours once again omitting estimates for covariates. For smoking, there is no association between changes in time preferences and behaviours. A greater preference for spending discretionary income is positively associated with heavy drinking but the small coefficient means the indirect mediated effect from financial strain to heavy drinking is almost trivial at $0.002\left(0.066^{*} 0.037, p=0.047\right)$. The mediated effect of strain on being overweight through changes in difficulty controlling expenditure is statistically significant but also small 
at $0.007\left(0.177^{*} 0.040, p=0.000\right)$. There is no significant direct effect of strain on smoking, heavy drinking or being overweight.

\section{Discussion}

We first considered the response of self-reported health to financial strain and estimate the proportion of the response mediated by changes in health behaviours. Financial strain has a significant and sizeable negative direct effect on self-reported health. This result is noteworthy in itself as many studies relating financial difficulties and health do not clearly establish the direction of causation and do not fully account for confounders Berkman et al., 2014). The indirect effects mediated through changes in health behaviours are small in comparison. Over the three-year timeframe considered the behavioural change pathway only mediates $4.9 \%$ of the effect of financial strain on health indicating that the biological pathway from financial strain to illness may be more significant than the influence of financial strain on the regulation of health-related behaviours. Economic stresses therefore appear to be distinct from other forms of stresses where negative associations with health-related behaviours have been extensively documented (Gerber and Pühse, 2009).

We find evidence that the lack of behavioural response to strain is due to higher intertemporal discounting having little effect on health behaviours. There is a significant increase in three out of four time preference measures in our sample as a result of financial strain particularly for difficulty controlling expenditure. This provides support to the view that the self-control required to regulate behaviours could be diminished by the mental effort required in dealing with financial difficulties (Vohs, 2013). However, there is surprisingly little response of health behaviours to changes in time preferences. None of the four time preference measures are associated with smoking, while only spending discretionary income significantly affects heavy drinking and only difficulty controlling expenditure affects being overweight. The overall response of health behaviour to financial strain mediated by time 
preferences is therefore very slight. This may be explained by the influence of the force of present-biases increasing demand for each unhealthy consumption good (i.e. alcohol, cigarettes and fast-food) being outweighed by the reduction in demand due to the lack of disposable income available to the financially-strained (French and McKillop, 2016). In a narrative review, Karanikolos et al. (2016) similarly find lower overall alcohol consumption and improved diet as a result of the financial crisis in developed countries which they attribute to reductions in disposable income. It is also plausible that people might eat less as a result of financial strain (e.g. because of stress and anxiety). Policy interventions suggested elsewhere such as therapies to improve impulse control are therefore likely to have limited efficacy in preventing illness for those with financial difficulties (Fields et al. 2014$)$. There is no additional direct effect of strain on health behaviours unrelated to time discounting. A direct effect might have been expected given studies indicating individuals dampen psychological arousal to stress by engaging in unhealthy behaviours Kassel et al., 2003, Ensel and Lin, 2004).

This study utilizes nationally-representative data which permits longitudinal analysis of causation and thus addresses many of the methodological concerns pervasive in the literature on economic stresses and health. There are however a number of limitations to any conclusions that can be drawn from this work. A fairer test of the competing pathways would include measures of the biological response to stress (e.g. inflammatory biomarkers, levels of glucose control) in order to provide directly comparable estimates for biological and behavioural pathways. Data on some health behaviours also associated with stress were not available and could provide additional explanatory power e.g. physical exercise, disturbed sleep and poor adherence to medical regimens (Vedhara, 2005). Also, more nuanced questions on changes in health behaviours might show different results. The model considered in the analysis examined effects of financial strain on health over a 3-year window but taking measures at annual intervals may miss much of the more immediate responses of health behaviours to strain thus misrepresenting effect sizes (Cole and Maxwell, 2003). 


\section{Conclusion}

In this paper, we conduct a longitudinal mediation analysis of the Dutch National Bank Household Survey to examine the causal relationship from financial strain to health and the degree to which this relationship is mediated through changes in health behaviours. Despite evidence from a number of studies showing the association between stress and unhealthy behaviours, we find that only $4.9 \%$ of the response of self-reported health to financial strain is mediated by changes in smoking, heavy drinking and body mass. Economic stresses therefore appear to be distinct from other forms of stress in the relatively minor influence of nonbiological pathways to ill-health. We carry out a second mediation analysis to understand this lack of behavioural response as other authors have linked stress to intertemporal discounting and from intertemporal discounting to changes in health behaviours. We find evidence that financial strain causes greater impulsivity but this does not lead to worse health behaviours. Our conjecture is that the financially-strained experience a reduction in disposable income which lowers demand for unhealthy goods to a greater extent than the opposing increase in present-biases raises demand for these goods. 


\section{Appendix}

The following questions were used to calculate the Consideration of Future Consequences (CFC) scale. Questions 1,2,6,7 and 8 were recoded so that a higher score consistently indicated a more present focus.

Now we present you with some statements about the future. Please indicate on a scale from 1 to 7 to what extent you agree with the following statements. 1 means 'extremely uncharacteristic' 7 means 'extremely characteristic'

1. I think about how things can change in the future, and try to influence those things in my everyday life.

2. I often work on things that will only pay off in a couple of years.

3. I am only concerned about the present, because I trust that things will work themselves out in the future.

4. With everything I do, I am only concerned about the immediate consequences (say a period of a couple of days or weeks).

5. Whether something is convenient for me or not, to a large extent determines the decisions that I take or the actions that I undertake.

6. I am willing to sacrifice my well-being in the present to achieve certain goals in the future.

7. I think it is important to take warnings about negative consequences of my acts seriously, even if these negative consequences would only occur in the distant future.

8. I think it is more important to work on things that have important consequences in the future, than to work on things that have immediate but less important consequences.

9. In general, I ignore warnings about future problems because I think these problems will be solved before they get critical.

10. I think there is no need to sacrifice things now for problems that lie in the future, because it will always be possible to solve these future problems later.

11. I only respond to urgent problems, trusting that problems that come up later can be solved in a later stage.

Notes : A twelfth question added from 2004 was not included in the CFC scale. The wording was changed slightly in 2005 from 1 means 'totally disagree' 7 means 'totally agree' to 1 means 'extremely uncharacteristic' 7 means 'extremely characteristic'. 


\section{References}

Adams, J. (2009). The mediating role of time perspective in socio-economic inequalities in smoking and physical activity in older english adults. Journal of Health Psychology 14 (6), 794-799.

Berkman, L. F., I. Kawachi, and M. M. Glymour (2014). Social Epidemiology. Oxford University Press.

Borghans, L. and B. H. Golsteyn (2006). Time discounting and the body mass index: Evidence from the Netherlands. Economics \& Human Biology 4 (1), 39-61.

Boyle, P. A., L. Yu, K. J. Gamble, and D. A. Bennett (2013). Temporal discounting is associated with an increased risk of mortality among community-based older persons without dementia. PloS One 8(6), e67376.

Broadbent, E., A. Kahokehr, R. J. Booth, J. Thomas, J. A. Windsor, C. M. Buchanan, B. R. Wheeler, T. Sammour, and A. G. Hill (2012). A brief relaxation intervention reduces stress and improves surgical wound healing response: a randomised trial. Brain, Behavior, and Immunity 26(2), 212-217.

Coffey, S. F., G. D. Gudleski, M. E. Saladin, and K. T. Brady (2003). Impulsivity and rapid discounting of delayed hypothetical rewards in cocaine-dependent individuals. Experimental and Clinical Psychopharmacology 11(1), 18.

Cohen, S., D. Janicki-Deverts, and G. E. Miller (2007). Psychological stress and disease. Journal of American Medical Asssociation 298(14), 1685-1687.

Cole, D. A. and S. E. Maxwell (2003). Testing mediational models with longitudinal data: questions and tips in the use of structural equation modeling. Journal of Abnormal Psychology 112(4), 558.

Enders, C. K. (2010). Applied missing data analysis. Guilford Press.

Ensel, W. M. and N. Lin (2004). Physical fitness and the stress process. Journal of Community Psychology 32(1), 81-101.

Eurobarometer (2015). What issues are Europeans most concerned about? Accessed at http://ec.europa.eu/publicopinion/topics/fs3challenges40en.pdf.

Feng, D., C. Zhen, and M. Silverstein (2013). Missing data and attrition in. Longtitudinal Data Analysis ed. Newsom, J.T. Jones, R.N. and Hofer, S.M., 71-96.

Fields, S. A., K. Lange, A. Ramos, S. Thamotharan, and F. Rassu (2014). The relationship between stress and delay discounting: a meta-analytic review. Behavioural pharmacology 25(5 and 6), 434-444.

Franks, P., M. R. Gold, and K. Fiscella (2003). Sociodemographics, self-rated health, and mortality in the US. Social Science 86 Medicine 56(12), 2505-2514.

Frederick, S., G. Loewenstein, and T. O'donoghue (2002). Time discounting and time preference: A critical review. Journal of Economic Literature 40(2), 351-401. 
French, D. and D. McKillop (2016). The Impact of debt and financial stress on health in Northern Irish households. Journal of European Social Policy forthcoming.

Gerber, M. and U. Pühse (2009). Review article: do exercise and fitness protect against stressinduced health complaints? a review of the literature. Scandinavian journal of public health $37(8)$, 801-819.

Gorelick, M. H. (2006). Bias arising from missing data in predictive models. Journal of Clinical Epidemiology 59(10), 1115-1123.

Graham, J. W., A. E. Olchowski, and T. D. Gilreath (2007). How many imputations are really needed? some practical clarifications of multiple imputation theory. Prevention Science 8(3), 206-213.

Haushofer, J., C. Jang, and J. Lynham (2015). Stress and temporal discounting: Do domains matter? https://pdfs.semanticscholar.org.

Idler, E. L. and Y. Benyamini (1997). Self-rated health and mortality: a review of twenty-seven community studies. Journal of Health and Social Behavior, 21-37.

Ikeda, S., M.-I. Kang, and F. Ohtake (2016). Hyperbolic discounting, the sign effect, and the body mass index. In Behavioral Economics of Preferences, Choices, and Happiness, pp. 277-313. Springer.

Janssen, K. J., A. R. T. Donders, F. E. Harrell, Y. Vergouwe, Q. Chen, D. E. Grobbee, and K. G. Moons (2010). Missing covariate data in medical research: to impute is better than to ignore. Journal of Clinical Epidemiology 63(7), 721-727.

Karanikolos, M., P. Heino, M. McKee, D. Stuckler, and H. Legido-Quigley (2016). Effects of the global financial crisis on health in high-income oecd countries a narrative review. International Journal of Health Services 46(2), 208-240.

Kassel, J. D., L. R. Stroud, and C. A. Paronis (2003). Smoking, stress, and negative affect: correlation, causation, and context across stages of smoking. Psychological Bulletin 129(2), 270.

Kristman, V., M. Manno, and P. Côté (2004). Loss to follow-up in cohort studies: how much is too much? European Journal of Epidemiology 19(8), 751-760.

Leonard, T., K. Shuval, A. de Oliveira, C. S. Skinner, C. Eckel, and J. C. Murdoch (2013). Health behavior and behavioral economics: economic preferences and physical activity stages of change in a low-income African-American community. American Journal of Health Promotion 27(4), 211-221.

Lusardi, A. (1998). On the importance of the precautionary saving motive. The American Economic Review 88(2), 449-453.

MacKillop, J. and C. W. Kahler (2009). Delayed reward discounting predicts treatment response for heavy drinkers receiving smoking cessation treatment. Drug and Alcohol Dependence 104(3), 197-203. 
Marsiglia, F. F., S. T. Yabiku, S. Kulis, T. Nieri, and B. Lewin (2010). Influences of school Latino composition and linguistic acculturation on a prevention program for youths. Social Work Research 34(1), 6-19.

Mavaddat, N., A. L. Kinmonth, S. Sanderson, P. Surtees, S. Bingham, and K. T. Khaw (2011). What determines self-rated health ( $\mathrm{srh})$ ? a cross-sectional study of sf-36 health domains in the epic-norfolk cohort. Journal of Epidemiology and Community Health 65 (9), 800-806.

Newsom, J., R. N. Jones, and S. M. Hofer (2013). Longitudinal data analysis: A practical guide for researchers in aging, health, and social sciences. Routledge.

Nyhus, E. K. (2002). Psychological determinants of household saving behaviour. Norwegian School of Economics and Business Administration Ph.D. dissertation.

Pedersen, A., R. Zachariae, and D. H. Bovbjerg (2010). Influence of psychological stress on upper respiratory infectiona meta-analysis of prospective studies. Psychosomatic Medicine 72(8), 823832.

Peretti-Watel, P., O. LHaridon, and V. Seror (2013). Time preferences, socioeconomic status and smokers behaviour, attitudes and risk awareness. The European Journal of Public Health 23(5), $783-88$.

Picone, G., F. Sloan, and D. Taylor Jr (2004). Effects of risk and time preference and expected longevity on demand for medical tests. Journal of Risk and Uncertainty 28(1), 39-53.

Popova, S., J. Rehm, J. Patra, and W. Zatonski (2007). Comparing alcohol consumption in central and eastern Europe to other European countries. Alcohol and Alcoholism 42(5), 465-473.

Porcelli, B., A. Pozza, N. Bizzaro, A. Fagiolini, M.-C. Costantini, L. Terzuoli, and F. Ferretti (2016). Association between stressful life events and autoimmune diseases: A systematic review and meta-analysis of retrospective case-control studies. Autoimmunity Reviews 15(4), 325-334.

Rabinovich, A. and P. Webley (2007). Filling the gap between planning and doing: Psychological factors involved in the successful implementation of saving intention. Journal of Economic Psychology 28(4), 444-461.

Remor, E., F. Penedo, B. Shen, and N. Schneiderman (2007). Perceived stress is associated with CD4+ cell decline in men and women living with HIV/AIDS in Spain. AIDS Care 19(2), 215-219.

Richardson, S., J. A. Shaffer, L. Falzon, D. Krupka, K. W. Davidson, and D. Edmondson (2012). Meta-analysis of perceived stress and its association with incident coronary heart disease. The American Journal of Cardiology 110(12), 1711-1716.

Ritzema, H. (1992). An extended and behavioral life cycle model: The intermediary role of time preference. In Fourth international conference of the SASEUC.

Rubin Donald, B. (1987). Multiple imputation for nonresponse in surveys. New York: Wiley.

Samwick, A. A. (1998). Discount rate heterogeneity and social security reform. Journal of Development Economics 57(1), 117-146.

Schafer, J. L. (1997). Analysis of incomplete multivariate data. CRC press. 
Sobel, M. E. (1982). Asymptotic confidence intervals for indirect effects in structural equation models. Sociological Methodology 13(1982), 290-312.

Sterne, J. A., I. R. White, J. B. Carlin, M. Spratt, P. Royston, M. G. Kenward, A. M. Wood, and J. R. Carpenter (2009). Multiple imputation for missing data in epidemiological and clinical research: potential and pitfalls. British Medical Journal 338, b2393.

Strathman, A., F. Gleicher, D. S. Boninger, and C. S. Edwards (1994). The consideration of future consequences: weighing immediate and distant outcomes of behavior. Journal of Personality and Social Psychology 66(4), 742.

van der Pol, M., D. Hennessy, and B. Manns (2016). The role of time and risk preferences in adherence to physician advice on health behavior change. The European Journal of Health Economics, $1-14$.

van Huizen, T. and J. Plantenga (2013). Job Search Behaviour and Time Preferences: Evidence from the Netherlands. Discussion Paper Series/Tjalling C. Koopmans Research Institute 13(03).

Vedhara, K. (2005). Human Psychoneuroimmunology. Oxford University Press on Demand.

Vohs, K. D. (2013). The poor's poor mental power. Science 341(6149), 969-970.

Webley, P. and E. K. Nyhus (2006). Parents influence on childrens future orientation and saving. Journal of Economic Psychology 27(1), 140-164. 
Fig. 1: Three-wave autoregressive model of the effect of financial strain $\left(S_{i, t-2}\right)$ on health outcome $\left(Y_{i, t}\right)$ mediated by changes in $M_{i, t-1}$

Wave $\mathrm{t}-2 \quad$ Wave $\mathrm{t}-1 \quad$ Wave $\mathrm{t}$

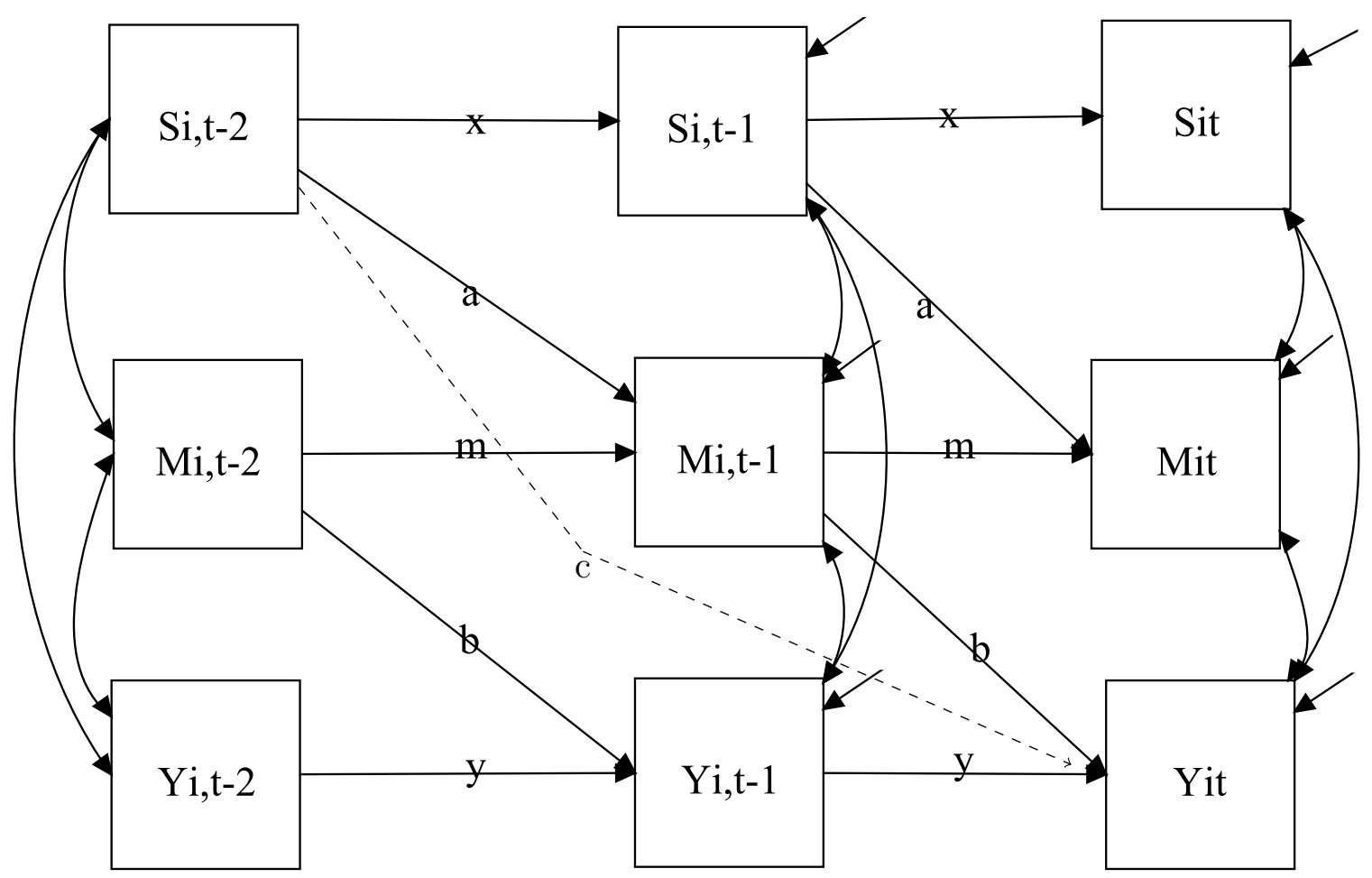

Notes : Financial strain, $S_{i t}$, is governed by a simple autoregressive model where the only explanatory variable is its own lag $S_{i, t-1}$. The mediating variable, $M_{i t}$, is also autoregressive but is additionally affected by demographic and household controls and lagged financial strain $S_{i, t-1}$. Health outcomes, $Y_{i t}$, are autoregressive, affected by controls and also affected by financial strain from two periods before $\left(S_{i, t-2}\right)$ both directly and indirectly through changes in the mediator $M_{i, t-1}$. Single-headed arrows at corners are variance terms. Double-headed arrows are covariance terms. 
Table 1: Descriptive statistics $(N=43858)$

\begin{tabular}{|c|c|c|c|}
\hline & $\overline{\mathrm{n}}$ & $\%$ & (\% non-missing) \\
\hline \multicolumn{4}{|l|}{ Financial strain } \\
\hline Yes & 5445 & 12.4 & $(20.9)$ \\
\hline No & 20663 & 47.1 & $(79.1)$ \\
\hline Missing & 17750 & 40.5 & - \\
\hline \multicolumn{4}{|l|}{ Health } \\
\hline Excellent/Good & 21535 & 49.1 & $(77.9)$ \\
\hline Fair/Not so good/Poor & 6124 & 14.0 & $(22.1)$ \\
\hline Missing & 16199 & 36.9 & - \\
\hline \multicolumn{4}{|l|}{ Smoking } \\
\hline Yes & 6449 & 14.7 & $(23.3)$ \\
\hline No & 21210 & 48.4 & $(76.7)$ \\
\hline Missing & 16199 & 36.9 & - \\
\hline \multicolumn{4}{|l|}{ Heavy drinking } \\
\hline Yes & 1866 & 4.3 & $(6.7)$ \\
\hline No & 25793 & 58.8 & $(93.3)$ \\
\hline Missing & 16199 & 36.9 & - \\
\hline \multicolumn{4}{|l|}{ Overweight } \\
\hline Yes & 13972 & 31.9 & $(50.5)$ \\
\hline No & 13684 & 31.2 & $(49.5)$ \\
\hline Missing & 16202 & 36.9 & - \\
\hline \multicolumn{4}{|l|}{ Time horizons } \\
\hline$>10$ years & 1123 & 2.6 & $(4.2)$ \\
\hline $5+$ years & 3311 & 7.5 & $(12.4)$ \\
\hline Next couple of years & 7734 & 17.6 & $(28.9)$ \\
\hline Next year & 6194 & 14.1 & $(23.1)$ \\
\hline Next couple of months & 8394 & 19.1 & $(31.4)$ \\
\hline Missing & 17102 & 38.1 & - \\
\hline \multicolumn{4}{|l|}{ Spending discretionary income } \\
\hline $1=$ Save as much as possible & 1919 & 4.4 & $(7.3)$ \\
\hline 2 & 6834 & 15.6 & $(25.9)$ \\
\hline 3 & 8682 & 19.8 & $(32.9)$ \\
\hline 4 & 6124 & 14.0 & $(23.2)$ \\
\hline 5 & 1752 & 4.0 & $(6.6)$ \\
\hline 6 & 798 & 1.8 & $(0.9)$ \\
\hline $7=$ Spend money immediately & 242 & 0.6 & $(10.6)$ \\
\hline Missing & 17507 & 39.9 & - \\
\hline \multicolumn{4}{|l|}{ Difficulty controlling expenditure } \\
\hline $1=$ Very easy & 4809 & 11.0 & $(18.2)$ \\
\hline 2 & 8364 & 19.1 & $(31.6)$ \\
\hline 3 & 4509 & 10.3 & $(17.0)$ \\
\hline 4 & 4358 & 9.9 & $(16.5)$ \\
\hline 5 & 2920 & 6.7 & $(11.0)$ \\
\hline 6 & 1213 & 2.8 & $(4.6)$ \\
\hline $7=$ Very difficult & 280 & 0.6 & (1.1) \\
\hline
\end{tabular}




\begin{tabular}{|c|c|c|c|}
\hline Missing & 17367 & 38.1 & - \\
\hline \multicolumn{4}{|c|}{ Consideration of future consequences } \\
\hline Mean and SD & 4.1 & 0.7 & \\
\hline Missing & 26250 & 59.9 & \\
\hline \multicolumn{4}{|l|}{ Sex } \\
\hline Male & 22004 & 50.2 & \\
\hline Female & 21854 & 49.8 & \\
\hline \multicolumn{4}{|c|}{ Highest level of education attended } \\
\hline Primary & 24126 & 55.0 & $(55.2)$ \\
\hline Secondary & 15200 & 34.7 & $(34.8)$ \\
\hline University & 4372 & 10.0 & $(10.0)$ \\
\hline Missing & 160 & 0.4 & - \\
\hline \multicolumn{4}{|l|}{ Employed } \\
\hline Yes & 21666 & 49.4 & $(49.4)$ \\
\hline No & 22177 & 50.6 & $(50.9)$ \\
\hline Missing & 15 & 0.0 & - \\
\hline \multicolumn{4}{|l|}{ Partner } \\
\hline Yes & 36672 & 83.6 & $(83.6)$ \\
\hline No & 7184 & 16.4 & $(16.4)$ \\
\hline Missing & 2 & 0.0 & - \\
\hline \multicolumn{4}{|l|}{ No. of children } \\
\hline Mean and SD & 0.9 & 1.1 & \\
\hline Missing & 2 & 0.0 & \\
\hline \multicolumn{4}{|l|}{ Homeowner } \\
\hline Yes & 14162 & 32.3 & $(70.9)$ \\
\hline No & 5822 & 13.3 & $(19.6)$ \\
\hline Missing & 23874 & 54.4 & - \\
\hline \multicolumn{4}{|l|}{ Age } \\
\hline Mean and SD & 50.7 & 16.2 & \\
\hline Missing & 488 & 1.1 & \\
\hline \multicolumn{4}{|c|}{ Annual household net income $(€)$} \\
\hline Mean and SD & 36975 & 70206 & \\
\hline Missing & 23280 & 51.1 & \\
\hline
\end{tabular}

Notes : All observations for those persons aged 16 and over in households participating in three consecutive waves of the CentERpanel. In 2002, the guilder was replaced by the euro at an exchange rate of 2.20371 guilders $=1 €$. All income values before 2003 are converted to $€$ at this exchange rate. 
Table 2: Structural equation model estimates of the effects of financial strain on self-reported health mediated by changes in health behaviours $(n=43226)$

Panel A : Effect of financial strain on mediators

\begin{tabular}{lcccccc}
\hline & \multicolumn{5}{c}{ Health behaviours at t-1 } \\
\cline { 2 - 7 } & \multicolumn{2}{c}{ Smoking } & Heavy drinking & \multicolumn{2}{c}{ Overweight } \\
\hline Financial strain at t-2 & 0.026 & $(0.050)$ & $0.111^{*}$ & $(0.051)$ & 0.044 & $(0.036)$ \\
Control variables & & & & & & \\
Health behaviour at t-2 & $3.297^{* *}$ & $(0.042)$ & $2.389^{*}$ & $(0.045)$ & $2.613^{* *}$ & $(0.030)$ \\
Age & $-0.005^{* *}$ & $(0.001)$ & 0.003 & $(0.002)$ & $0.005^{* *}$ & $(0.001)$ \\
Female & -0.028 & $(0.033)$ & $-0.339^{* *}$ & $(0.038)$ & $-0.068^{* *}$ & $(0.023)$ \\
Education - secondary & $-0.138^{* *}$ & $(0.036)$ & 0.000 & $(0.039)$ & $-0.098^{* *}$ & $(0.024)$ \\
Education - university & $-0.176^{* *}$ & $(0.060)$ & 0.040 & $(0.059)$ & $-0.212^{* *}$ & $(0.041)$ \\
Employed & $0.089^{*}$ & $(0.037)$ & 0.027 & $(0.039)$ & $0.193^{* *}$ & $(0.029)$ \\
Has partner & $-0.103^{*}$ & $(0.049)$ & -0.073 & $(0.048)$ & 0.014 & $(0.031)$ \\
No. of children & 0.016 & $(0.016)$ & $-0.040^{*}$ & $(0.019)$ & -0.008 & $(0.012)$ \\
Income (log) & -0.070 & $(0.043)$ & 0.065 & $(0.043)$ & 0.033 & $(0.032)$ \\
Homeowner & $-0.126^{*}$ & $(0.052)$ & 0.023 & $(0.048)$ & -0.036 & $(0.033)$ \\
\hline \hline
\end{tabular}

Panel B : Effect of mediators on health

\begin{tabular}{lcc}
\hline & \multicolumn{2}{c}{ Health at t } \\
\hline Health behaviours at $t-1$ & & \\
Smoking & $-0.080^{* *}$ & $(0.019)$ \\
Heavy drinking & -0.012 & $(0.033)$ \\
Overweight & $-0.034^{* *}$ & $(0.017)$ \\
Control variables & & \\
Health at t-1 & $1.819^{* *}$ & $(0.015)$ \\
Age & $0.005^{* *}$ & $(0.001)$ \\
Female & $-0.147^{* *}$ & $(0.015)$ \\
Education - secondary & $0.067^{* *}$ & $(0.016)$ \\
Education - university & $0.133^{* *}$ & $(0.026)$ \\
Employed & $0.130^{* *}$ & $(0.017)$ \\
Has partner & $-0.102^{* *}$ & $(0.022)$ \\
No. of children & 0.004 & $(0.008)$ \\
Income (log) & $-0.070^{* *}$ & $(0.022)$ \\
Homeowner & 0.046 & $(0.026)$ \\
Direct effect of strain at $t-2$ & $-0.091^{* *}$ & $(0.024)$ \\
\hline \hline
\end{tabular}

Panel C : Autoregressive model of financial strain

\begin{tabular}{lll}
\hline \hline & \multicolumn{2}{l}{ Financial strain at t } \\
\hline Financial strain at t-1 & $1.148^{* *}$ & $(0.030)$ \\
\hline \hline
\end{tabular}

Notes : The first row of estimates in Panel A corresponds to parameter a in figure 1 where there are three potential mediators. In Panel B, the first three rows of estimates correspond to parameter $\mathrm{b}$ in figure 1 where there are three potential mediators and the direct effect corresponds to parameter c. Residual covariances have been omitted. Full results are available in online appendix. ${ }^{*} p<0.05,{ }^{* *} p<0.01$ 
Table 3: Structural equation model estimates of the effects of financial strain on health behaviours mediated by changes in time preferences $(n=43140)$

Panel A : Effect of financial strain on mediators

\begin{tabular}{|c|c|c|c|c|c|c|c|c|}
\hline & \multicolumn{8}{|c|}{ Time preferences at t-1 } \\
\hline & \multicolumn{2}{|c|}{ Time horizons } & \multicolumn{2}{|c|}{$\begin{array}{c}\text { Spending } \\
\text { discretionary } \\
\text { income }\end{array}$} & \multicolumn{2}{|c|}{$\begin{array}{c}\text { Difficulty } \\
\text { controlling } \\
\text { expenditure }\end{array}$} & \multicolumn{2}{|c|}{$\begin{array}{l}\text { Consideration } \\
\text { of future } \\
\text { consequences }\end{array}$} \\
\hline $\begin{array}{l}\text { Financial strain at t-2 } \\
\text { Control variables }\end{array}$ & $0.045^{*}$ & $(0.021)$ & $0.066^{* *}$ & $(0.022)$ & $0.177^{* *}$ & $(0.020)$ & -0.010 & $(0.015)$ \\
\hline Time preferences at t-2 & $0.374^{* *}$ & $(0.007)$ & $0.535^{* *}$ & $(0.006)$ & $0.454^{* *}$ & $(0.005)$ & $0.504^{* *}$ & $(0.007)$ \\
\hline Age & -0.001 & $(0.001)$ & $-0.004^{* *}$ & $(0.001)$ & $-0.005^{* *}$ & $(0.001)$ & $.003^{* *}$ & $(0.000)$ \\
\hline Female & -0.007 & $(0.015)$ & $-0.030^{*}$ & $(0.013)$ & $0.052^{* *}$ & $(0.014)$ & $0.032^{* *}$ & $(0.010)$ \\
\hline Education - & $-0.036^{*}$ & $(0.015)$ & $0.065^{* *}$ & $(0.015)$ & $-0.052^{* *}$ & $(0.017)$ & $-0.057^{* *}$ & $(0.010)$ \\
\hline Educ & $-0.050^{*}$ & $(0.023)$ & 0.003 & $(0.024)$ & $-0.055^{*}$ & $(0.023)$ & $-0.177^{* *}$ & $(0.018)$ \\
\hline Empl & $-0.099 * *$ & $(0.016)$ & 0.020 & $(0.018)$ & $0.037^{*}$ & $(0.017)$ & -0.019 & $(0.011)$ \\
\hline Has & -0.020 & $(0.020)$ & 0.008 & $(0.019)$ & $0.103^{* *}$ & $(0.020)$ & 0.010 & $(0.013)$ \\
\hline No. & 0.007 & $(0.007)$ & 0.006 & $(0.008)$ & $0.046^{* *}$ & $(0.007)$ & 0.001 & $(0.006)$ \\
\hline Income (log) & $-0.062^{* *}$ & $(0.019)$ & 0.020 & $(0.018)$ & $-0.072^{* *}$ & $(0.020)$ & -0.018 & $(0.015)$ \\
\hline Homeowner & $-0.136^{* *}$ & $(0.020)$ & $-0.048^{*}$ & $(0.021)$ & $-0.045^{*}$ & $(0.020)$ & $-0.047^{* *}$ & $(0.016)$ \\
\hline
\end{tabular}

Panel B : Effect of mediators on health behaviours

\begin{tabular}{lcccccc}
\hline \hline & \multicolumn{7}{c}{ Health behaviour at t } \\
\cline { 2 - 7 } & \multicolumn{2}{c}{ Smoking } & Heavy drinking & Overweight \\
\hline Time preferences at $t-1$ & & & & & & \\
Time horizons & -0.016 & $(0.015)$ & -0.001 & $(0.016)$ & 0.002 & $(0.011)$ \\
Spending discretionary income & 0.025 & $(0.015)$ & $0.037^{*}$ & $(0.015)$ & 0.020 & $(0.011)$ \\
Difficulty controlling expenditure & 0.000 & $(0.012)$ & -0.004 & $(0.013)$ & $0.040^{* *}$ & $(0.008)$ \\
Consideration of future consequences & 0.020 & $(0.032)$ & 0.039 & $(0.029)$ & 0.011 & $(0.021)$ \\
Control variables & & & & & & \\
Health behaviour at t-1 & $3.320^{* *}$ & $(0.042)$ & $2.464^{* *}$ & $(0.045)$ & $2.615^{* *}$ & $(0.029)$ \\
Age & $-0.005^{* *}$ & $(0.001)$ & 0.002 & $(0.002)$ & $0.006^{* *}$ & $(0.001)$ \\
Female & -0.035 & $(0.033)$ & $-0.328^{* *}$ & $(0.038)$ & $-0.065^{* *}$ & $(0.023)$ \\
Education - secondary & $-0.130^{* *}$ & $(0.036)$ & -0.028 & $(0.038)$ & $-0.091^{* *}$ & $(0.024)$ \\
Education - university & $-0.145^{*}$ & $(0.061)$ & 0.005 & $(0.058)$ & $-0.196^{* *}$ & $(0.041)$ \\
Employed & $0.071^{*}$ & $(0.036)$ & 0.046 & $(0.040)$ & $0.175^{* *}$ & $(0.029)$ \\
Has partner & $-0.107^{*}$ & $(0.049)$ & -0.079 & $(0.049)$ & 0.020 & $(0.031)$ \\
No. of children & 0.014 & $(0.016)$ & $-0.045^{*}$ & $(0.019)$ & -0.013 & $(0.012)$ \\
Income (log) & -0.069 & $(0.043)$ & 0.057 & $(0.044)$ & 0.035 & $(0.033)$ \\
Homeowner & $-0.118^{*}$ & $(0.053)$ & -0.009 & $(0.048)$ & -0.016 & $(0.033)$ \\
Direct effect of strain at $t-2$ & -0.008 & $(0.053)$ & 0.000 & $(0.056)$ & 0.047 & $(0.037)$ \\
\hline \hline
\end{tabular}

Panel C : Autoregressive model of financial strain

Financial strain at $\mathrm{t}$

Financial strain at t-1 $1.099^{* *} \quad(0.031)$


Notes : Panel A is re-estimated for each health behaviour but results are practically unchanged. The results given are for the 'Overweight' estimation. The first row of estimates in Panel A corresponds to parameter a in figure 1 where there are four potential mediators. In Panel $\mathrm{B}$, the first four rows of estimates correspond to parameter $\mathrm{b}$ in figure 1 where there are four potential mediators and the direct effect corresponds to parameter $\mathrm{c}$. Residual covariances have been omitted. Full results are available in online appendix. ${ }^{*} p<0.05,{ }^{* *} p<0.01$ 